This is the author's version of the article, the published version can be downloaded on the journal's website (see link below):

Mintchev, N. (2018) From Incommensurability to Dialogue: A Response to David Lichtenstein, Psychoanalytic Dialogues, 28:2, 257-263.

https://www.tandfonline.com/doi/full/10.1080/10481885.2018.1432961

David Lichtenstein's commentary on my article "Object-Relations and Cultural Narratives in the Analysis of Racism can be downloaded here:

Lichtenstein, D (2018) Commentary on Nikolay Mintchev's “Object- Relations and Cultural Narratives in the Analysis of Racism", Psychoanalytic Dialogues, 28:2, 250256.

https://www.tandfonline.com/doi/full/10.1080/10481885.2018.1432960

\title{
From Incommensurability to Dialogue: A response to David Lichtenstein
}

Nikolay Mintchev

\begin{abstract}
This response to David Lichtenstein explores the opportunities and challenges that arise from the conceptual pluralism within the field of psychoanalysis. It argues that the Kleinian and Lacanian theoretical frameworks are in many ways incommensurable, but it also maintains that this should not translate into an either/or approach that privileges one framework over the other. Acknowledging the foundational differences between Kleinian and Lacanian theories should not forestall the possibility of productive and mutually beneficial dialogue carried out in good faith.
\end{abstract}

David Lichtenstein's response to my article raises a number of questions about the nature of dialogue between the Kleinian and Lacanian systems of thought, and between different psychoanalytic theories in general. How, and to what extent, should we treat different psychoanalytic traditions as conceptually aligned? Do the Kleinian and Lacanian schools of thought present the same theory in different languages, or do they offer fundamentally different theoretical approaches to the unconscious, subjectivity and interpsychic relations? If they do indeed stand on different theoretical foundations, then what are the implications of this pluralism for dialogue and theoretical synthesis within the field of psychoanalysis? 
Lichtenstein's commentary is roughly comprised of two parts. In the first part he addresses my understanding of the difference between the Kleinian and Lacanian conceptual toolkits. He claims that (a) I treat the Kleinian and Lacanian models as fundamentally different in their theoretical approaches and also that (b) this is a mistake on my part. Here, I agree with Lichtenstein's reading of my argument - I do in fact consider the Kleinian and Lacanian theories to be in many ways incommensurable - but I do not agree with his assertion that arguing for this incommensurability is a mistake. I will explain why this is the case shortly.

In the second part of his response, Lichtenstein turns to my consideration of each theory. He claims that (c) I privilege the Lacanian/post-Lacanian framework because of its suitability for social analysis, which leads me to erroneously reject the importance of unconscious phantasy. In contrast to this alleged position, he then argues that (d) it is important to maintain a dialectic between language/culture on the one hand and unconscious phantasy on the other - a dialectic which he sees as missing from my analysis and my position on how we should understand identity and racism. Here, in this second part of the commentary, I disagree with Lichtenstein's reading of my argument and I distance myself from the position he attributes to me, but I do agree with his claim that it is necessary to maintain the aforementioned dialectic. As I show below, the intention of my article all along was not to privilege one theory over the other, but to argue that both object-relations and cultural narratives are indispensible for a sound understanding of unconscious phantasy, subjectivity and society.

But in addition to addressing Lichtenstein's points on their own terms, I think it is particularly interesting and intellectually productive to think about the relationship between the themes he raises in the first and second parts of his intervention as outlined above. My view is that his disagreement with me in the first part leads directly to his misreading of my argument in the second part - his commentary suggests that valorizing the differences between Kleinian and Lacanian theory means that a validation of both approaches is impossible. I address this issue in the conclusion where I suggest that taking both approaches seriously is in fact something we should strive for, despite the inherent contradictions that disrupt any attempt to create a unified theory. 


\section{Different foundations or a failure of translation?}

Lichtenstein's approach to the Klein-Lacan relationship is to focus on the similarities between the two schools of thought rather than on their differences. Lacan and Klein, as well as their followings, share a common commitment to the primacy of the Freudian unconscious, they are both profoundly sceptical of "egopsychology", and they have mutual respect for one another. Following this assertion of key commonalities Lichtenstein explains that the difference between the two schools is not a matter of "different foundations" as I argue, but rather an issue of translation - an instance in which shared psychoanalytic ideas are expressed in different vocabularies:

when contemporary followers of Lacan and Klein confront one another's work in good faith they engage in an effort of translation. They try to work out the extent to which they are talking about the same experiences in different languages or whether they are instead encountering an instance where differing representations in fact represent different foundations. But the latter view cannot be incontrovertibly assumed. It is a misreading to treat the field as fundamentally riven by these differences (p. xx).

Slightly later in his commentary, Lichtenstein suggests that the relationship between Kleinian and Lacanian psychoanalysis represents "a contingent and therefore potentially correctible failure of translation, a translation that if achieved would dissolve the apparently rigid boundaries or contradictions between the two approaches by better articulating what it is that they have in common" (p. xx). Thus, Lichtenstein sees Kleinian and Lacanian theory as the same theory expressed in different languages. This in turn leads him to a very peculiar notion of what it means for Kleinians and Lacanians to work together "in good faith" - a notion, furthermore, which I find difficult to agree with. According to him, working together in good faith means presuming that the two 
sides are fundamentally the same (as if that is a condition for seeing both as equally valuable). I would argue, however, that working in good faith means seeing value in a theory other than one's own. To work in good faith is to see value in theoretical differences and contradictions, not to claim that contradictions are "apparent" and that beneath the appearances the two sides are essentially saying the same thing (as if someone else's theory can only have value if it is the same as one's own).

I agree with Lichtenstein that both Kleinians and Lacanians are theorists and practitioners of psychoanalysis proper. But the general commonalities and shared commitments that he talks about do not foreclose the possibility of radically different approaches to Freudian concepts - approaches which cannot be reconciled with one another through a mere effort of translation and rearticulation. As Lichtenstein shows, drawing on Darian Leader's essay on unconscious phantasy, there is much that Lacanians and Kleinians can learn from each other to enrich their theories. But this intellectual exchange - which, by the way, I fully support - does not equate to theoretical compatibility or dissolution of boundaries.

Let me illustrate this last point using the notion of the symbolic, a theme which is particularly relevant for understanding unconscious phantasy and the relationship between the subject and reality. The symbolic is a key concept not just for Lacan, who emphasizes the impact of language on subjectivity, but also for Klein, who sees symbolism as "the foundation of all phantasy and sublimation" as well as "the subject's relation to the outside world and to reality in general" (Klein 1975 [1930]: 221).

A few years ago I wrote an article entitled "A Theoretical Impasse? The Concept of the Symbolic in Melanie Klein and Jacques Lacan" (Mintchev 2015). There, I examined the ways in which Klein and Lacan each theorise the symbolic function in psychoanalysis. My initial motivation for researching and writing that article was precisely a sense of unease and difficulty with translation across theories when thinking about the concept of the symbolic and discussing it with colleagues. Melanie Klein's key paper “The Importance of Symbol-Formation in the Development of the Ego" (1975 [1930]) offered a sophisticated and compelling account of how object-relations at the level of unconscious phantasy 
link with experiences of the external world to either hinder or enable a child's capacity to think symbolically. However, this brilliant description of the dynamics of symbol-formation stood at odds with Lacan's equally sophisticated ideas which reworked Ferdinand de Saussure's structural linguistics. Klein's theory emphasized the prominence of aggression, anxiety, and phantasies relating to the bodies of oneself and others, while Lacan's was about chains of signifiers, slippage of meaning and lalangue. Nevertheless, on the surface, the Kleinian and Lacanian theories seemed perfectly compatible with one another, save for their different vocabularies. They focused on different aspects of the symbolic function (ideographic symbolism for Klein and linguistic signification for Lacan) but they both had theories of image and word and so there was no reason to see them as incommensurable.

However, a closer look at the theoretical details revealed more fundamental differences. For example, from a developmental perspective Kleinians argue that experiences of objects and object-relations (which exist from birth) give rise to symbol-formation based on ideographic resemblance between shapes and movements, which in turn leads to the use of words as the most advanced form of symbolization. Lacanians see things differently. For them, the use of language does not derive from experiences of objects and objectrelations; on the contrary, they see the acquisition of language as both preceding and defining the experience of object-relations because it inscribes onto the subject a structure of difference which is seen as the defining feature of human thought. In this respect the Kleinian and Lacanian models are diametrically opposed: within the former model, development starts with objects and objectrelations and ends up with the use of language; within the latter, language is the condition of experiencing objects and object-relations. Both models describe the functioning of a dynamic unconscious, both are rigorously psychoanalytic, and both are firmly grounded in Freud's theories of the symbolic - one is based on Freud's notion of symbols based on resemblances between shapes and movements (Freud 1917), the other builds on his theory of "word-presentations" and "thing-presentations" (Freud 1915, 1923).

This difference in theorizing the symbolic function also translates into conflicting views about clinical practice. As Lichtenstein points out, the early 
Lacan had great respect for Klein's clinical virtuosity. But Lacan also thought that Klein was profoundly misguided in her practice. He addressed this issue directly in Seminar I where he commented on Klein's paper on symbol-formation and the clinical case study that she presented there (Lacan 1991 [1953-54]: ch. 6 and 7). Klein's analysand, a four-year old boy named Dick, had an immensely poor vocabulary for his age, disrupted syntax, and a notable lack of interest in engaging with those around him (Klein considered Dick to be schizophrenic, but today he would most likely be diagnosed with autism). Yet despite this, after a number of persistent interpretations which verbalized Dick's unconscious phantasies of object-relations, Klein was able to make significant progress in getting Dick to speak, and also to engage with people and things. But why was she successful? According to Klein's model of the mind, her interpretations reduced Dick's latent anxiety at the level of his object-relations. Dick's shutting off from reality had resulted from an excess of persecutory anxiety which had made him terrified of his own unconscious aggression. Klein believed that reducing anxiety allowed Dick to direct his aggression towards symbolformation and engagement with the outer world. She argued that her clinical intervention transformed the organization of Dick's object-relations, and this subsequently opened a pathway towards symbolic forms of thought. Lacan, however, disagreed with this view. According to him, what happened was not that Klein's interpretations reduced anxiety and allowed Dick to think symbolically, but rather that her use of language inscribed a symbolism onto Dick, which in turn changed his relation to reality. Klein's interpretation, according to Lacan, is "a superimposing [of symbolism] upon the subject" (1991 [1953-54]: 74), not an intervention in object-relations that enables the subject to use words.

So what can this discussion of the symbolic tell us about the relationship between the Lacanian and Kleinian schools of thought? The difference between the two theories, at least insofar as the symbolic is concerned, entails more than a mere difference of vocabularies. Finding a common language for translation is an important step towards fruitful intellectual exchange, but it can hardly dissolve the boundary between the Lacanian and Kleinian developmental schemes or their different views on the dynamics of clinical intervention. That is 
not to say that one should privilege object-relations over language or cultural narratives. As I argued with regard to the symbolic, working with both theories leads to tensions and challenges, but choosing a side is problematic as well (Mintchev 2015: 320-322). This, I claimed, calls for further dialogue between Kleinian and Lacanian concepts and a sharper understanding of how we can work with (as opposed to work against) the tensions that emerge from careful comparative work.

\section{Object-relations and cultural narratives}

It was within this context that I set out to explore if and how the Kleinian and Lacanian approaches lead to different understandings of racism, and whether a dialogue between the two could lead to original insights. However, since race and racism are at once psychological and social, I also drew on insights from social theory and social science in addition to psychoanalysis. The reason I did this was to add nuance to the psychoanalytic understanding of unconscious phantasy and cultural narratives as elements of subjectivity (not, as Lichtenstein suggests, to move away from psychoanalysis altogether). Once I began to think comparatively in that way, a tension between object-relations and cultural narratives immediately stood out. As I argue in the article, the types of objectrelations that Klein so carefully describes as defining features of interpsychic and intrapsychic life do not square up with cultural taxonomies of ethnic and racial self-other relations.

But this does not mean that I advocate for a narrative approach over an object-relational one, as Lichtenstein claims. The second part of Lichtenstein's commentary attributes to me a preference for the Lacanian/post-Lacanian framework - a reading of my argument that I do not agree with. I do indeed claim that scholars who take a Lacanian approach can more easily adapt psychoanalytic categories to social and historical specificities of self-other relations. This statement, however, is a description of the way in which theory has been used to make sense of social reality, not a prescription of how social reality ought to be theorized. Lichtenstein gives me credit for this at first. My 
view, he says, is that "the Lacanian vocabulary lends itself better than the Kleinian framework to perspectives that rely upon symbolic cultural practice [...]" (p. $\mathrm{xx}, \mathrm{my}$ emphasis). But this view of mine is then interpreted as a wholesale rejection of Kleinian theory, as well as a rejection of a balanced dialectic of cultural semiotics and unconscious phantasy. More specifically, my position is seen as being "against the granting [of] adequate weight to the intrapsychic pole of the dialectic" (p. xx). Lichtenstein elaborates this point as follows:

While I share Mintchev's interest in a psychoanalytic theory of the subject that recognizes the formative function of cultural semiotics, i.e. language in its broadest sense, not as a cognitive or secondary process but as essential to unconscious structure, I think that theory must also retain the regard for unconscious phantasy that is at the heart of the psychoanalytic subject. The dialectical question for psychoanalysis is how the subject's formation in language gives structure to unconscious phantasy. This is indeed a question that derives from both the Kleinian and Lacanian perspectives and indicates the extent to which they are a common project (p. xx).

I fully agree with Lichtenstein that unconscious phantasy - which, as I explain, forms the basis of object-relations (see p. 5-7) - is just as important as cultural semiotics for theorizing subjectivity, identity and racism. In fact, I make this point on a number of occasions throughout the text. For example, according to the abstract, "it is argued that both theories [Lacanian and Kleinian] are crucial for a robust analysis of racism" (p. 1). Then, in the article's opening section, this point is reiterated once again: "I argue that a theory of both object-relations and cultural narratives is essential for a psychoanalytic understanding of race and racism" (p. 2). After this, in the section on grammars of identity I present a clinical vignette which I read through Bauman's grammars to argue for their clinical relevance. There I say that the sudden change in the patient's view of the analyst "had a clear object-relational foundation at the level of interaction 
between two people. Yet at the same time, these object-relations were organized by a complex grammar of identity and difference [...] (p. 26)." Then again, in the conclusion to the article, I state that "the grammars of identity outlined above [...] integrate various forms of object-relations" (p. 27) before going on to explain why this is the case.

However, the clearest evidence that Lichtenstein's view and mine are in agreement is the fact that we even use the same language to express our positions. According to Lichtenstein, " $[\mathrm{t}]$ he dialectical question for psychoanalysis is how the subject's formation in language gives structure to unconscious phantasy" (p. $x x$, my emphasis). According to me "[t]hese grammars [...] of self-other representations act as an unconscious organizing framework that structures interactions between people in everyday social situations as well as in the clinic" (p. 21, my emphasis). Not only do we use the same key word (i.e., structure), but as this comparison of passages suggests the very aim of my article is to address the psychoanalytic question he poses about how language gives structure to unconscious phantasy and object-relations. And yet Lichtenstein quotes this very same passage by me to argue that I want "to build an exit from the psychoanalytic problem of psyche/social" (p. xx).

It is tempting to read this misunderstanding in light of the earlier discussion about theoretical foundations and translation. Here we have not only a shared theoretical foundation but also a shared language of expression - there is a two-fold alignment between us. But even then something has gone awry and this most promising of translations turns out to be a failed one. I think it is worth thinking about why that could be and what this tells us about the nature of psychoanalytic dialogue.

One possibility is that the misunderstanding I have described has something to do with the fact that I see the Lacanian and Kleinian theoretical foundations as divergent. After all, if we accept the existence of such a divergence, then dialogue becomes much more difficult than it would be if the differences in questions were only a matter of translation. For this reason, some people might see differences as hindering rather than helping the dialogic process. But what if we approach this difficulty from a different angle? What happens if we take the need for dialogue as our starting point and then we 
realize that we are working across difficult and potentially irreconcilable contradictions? I don't think that in such a case we should halt our efforts at creating dialogue or trying to integrate diverse theoretical insights. On the contrary, I think we should reaffirm the need for dialogue and further explore the dynamics of theorization and the question of how we can work with theoretical contradictions in addressing what happens in society and in the clinic. Theory has its limits in explaining how the mind works. Different psychoanalytic theories often focus on different aspects of subjectivity, which in turn allow us to achieve different outcomes. Sometimes these theories may work well together and at other times they might clash. But theoretical contradictions should not immediately lead to an either/or approach, where one approach is seen as wrong and the other as right. Psychoanalysis is not a unified theory and even Freud himself had changing and conflicting views on anything from anxiety and drive to symbolism and the topography of the mind. Divergences in theoretical foundations run deep in the history of psychoanalysis and finding a common language to discuss them is only the first step, not the conclusion, to a dialogue carried out in good faith.

\section{Bibliography}

Freud, S. (1915). The Unconscious. In The Standard Edition of the Complete Psychological Works of Sigmund Freud, Volume XIV (pp. 159-215). London: Hogarth.

Freud, S. (1916-1917). Introductory Lectures on Psychoanalysis, The standard edition of the complete psychological works of Sigmund Freud, vols. XVI$X V I I$. London: Hogarth.

Freud, S. (1923). The Ego and the Id. In The Standard Edition of the Complete Psychological Works of Sigmund Freud, Volume XIX (pp. 1-66). London: Hogarth.

Klein, M. (1975 [1930]), The Importance of Symbol-Formation in the

Development of the Ego, The Writings of Melanie Klein, I (pp. 219-232), London: Vintage.

Lacan, J. (1991 [1953-54]). Freud's Papers on Technique: The Seminar of Jacques Lacan, Book I. London: W.W. Norton and Company.

Mintchev, N. (2015). A Theoretical Impasse? The Concept of the Symbolic in Melanie Klein and Jacques Lacan. Psychoanalytische Perspectieven, 33(3), 307-324. 